\title{
Discovery of a new species belonging to the genus Heinrichiellus Tereshkin (Ichneumonidae, Ichneumoninae, Platylabini)
}

\author{
Namiki Kikuchi', Kazuhiko Konishi ${ }^{2}$ \\ I Systematic Entomology, Graduate School of Agriculture, Hokkaido University, Sapporo 060-8589, Japan \\ 2 Entomological Laboratory, Faculty of Agriculture, Ehime University, Tarumi 3-5-7, Matsuyama, Ehime \\ 790-8566, Japan
}

Corresponding author: Namiki Kikuchi (namikikikuchi@gmail.com)

Academic editor: Gavin Broad | Received 16 May 2015 | Accepted 12 June 2015 | Published 7 September 2015

http://zoobank.org/21426A28-DB22-47B2-9D55-1BFB72AA7764

Citation: Kikuchi N, Konishi K (2015) Discovery of a new species belonging to the genus Heinrichiellus Tereshkin (Ichneumonidae, Ichneumoninae, Platylabini). Journal of Hymenoptera Research 45: 31-40. doi: 10.3897/JHR.45.5301

\begin{abstract}
Herein, we describe a new species of the distinctive ichneumonine genus Heinrichiellus Tereshkin, H. nambui sp. n. from Japan. To our knowledge, this is the first record of the genus from Japan. A key to the species of Heinrichiellus is provided.
\end{abstract}

\section{Keywords}

Taxonomy, new species, Japan

\section{Introduction}

Heinrichiellus Tereshkin is a monotypic genus of the subfamily Ichneumoninae (Tereshkin 1996, 2009). The type locality of the type species Heinrichiellus hildegardae (Tereshkin) is Russian Far East, eastern Palearctic region. Because of its unique morphological features, such as the absence of an antennal cavity, extremely long and thin maxillary palpus, presence of sharp starnauli on the mesonotum, extremely slender and long legs, and long but not flattened metasomal petiole, the systematic position of 
Heinrichiellus had remained ambiguous (Tereshkin 1996). Recently, Tereshkin (2009) conducted a large study on the genera of the tribe Platylabini and placed Heinrichiellus in Platylabini, because of the following common characteristics: convex clypeus, slim and narrow mandibles, highly elevated scutellum, and amblypygous metasoma.

Platylabini includes 38 genera worldwide, 13 of which have been recorded from the eastern Palearctic region (Tereshkin 2009, Yu et al. 2012). Because Ichneumoninae is the most species rich subfamily of Japanese Ichneumonidae, faunistic and taxonomic studies of this subfamily are still insufficient. Although only 4 genera and 13 species of Platylabini have been recorded from Japan, considerably more species and genera are expected to exist in this country than those known previously.

In this study, we found a few Japanese specimens of the genus Heinrichiellus belonging to Platylabini. They exhibited some distinct differences compared to $H$. hildegardae; thus, we described another species of this peculiar genus.

\section{Materials and methods}

This study was conducted using the materials deposited at the National Institute for Agro-Environmental Sciences, Tsukuba (NIAES), and Ehime University Museum, Matsuyama (EUMJ). We also investigated the ichneumonid specimens from the collections of Hokkaido University, Osaka Museum of Natural History, Kanagawa Prefectural Museum of Natural History, and Tokyo Metropolitan University; however, no additional specimens of Heinrichiellus were found. The specimens were observed using a stereomicroscope (Olympus SZ60). Photographs were obtained at the Laboratory of Environmental Entomology, Ehime University, using a Nikon Digital Sight DS-Fi1 camera attached to a Leica S8APO stereomicroscope. Several partially focused images were combined using CombineZP@ (Hadley 2009). Morphological terminology is as per Gauld (1991). Microsculpture descriptions follow Eady (1968).

\section{Taxonomy}

\section{Genus Heinrichiellus Tereshkin, 2009}

Heinrichia Tereshkin, 1996: 86. Preoccupied by Heinrichia Stresemann, 1931.

Type species: Heinrichia hildegardae Tereshkin; monobasic.

Heinrichiella Tereshkin, 2000: 232. New name for Heinrichia Tereshkin, 1996. Preoccupied by Heinrichiella Hedwig, 1949.

Heinrichiellus Tereshkin, 2009: 1535. New name for Heinrichiella Tereshkin, 2000. Heinrichiola Kocak \& Kemal, 2009: 1. New name for Heinrichiella Tereshkin, 2000.

Diagnosis. This genus can be distinguished from other genera of Ichneumoninae on the basis of the following characteristics: head slightly transverse in dorsal view, ab- 
sence of antennal cavity, clypeus convex, sternaulus reaching base of mid coxa, highly elevated scutellum, propodeum with strongly developed and sharp apophysis, fore wing with large pentagonal areolet, all legs longer than fore wings, petiole long and not flattened, rounded in cross-section, gastrocoelus in the form of a longitudinal furrow with thyridium in the form of a small circle, metasoma amblypygous.

\section{Heinrichiellus nambui Kikuchi \& Konishi, sp. n.}

http://zoobank.org/A468C72C-792B-47BA-9348-4254FF355937

Figs $1-12$

Holotype. + , 35 $56^{\circ} \mathrm{N} 138^{\circ} 54^{\prime} \mathrm{E}$, Chichibu City, Saitama Prefecture, Honshu, Japan. Data on the label: "Green School, Ootaki, Saitama, Japan 10. VII. 1999 T. Nambu leg. [YPT \& MT]". Deposited in the collection of NIAES. Paratypes. 19 , “ $43^{\circ} 00^{\prime} \mathrm{N}$, 14124'E, Hitsujigaoka, Sapporo, Hokkaido, Japan, 20-27. viii. 2003, Malaise trap,

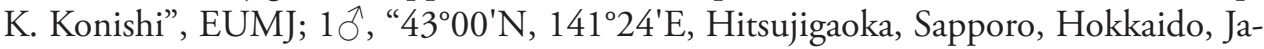
pan, 4-11. viii. 2008, Malaise trap, K. Konishi”, EUMJ.

Description of female. Head. Head 1.5 times as wide as long in dorsal view and coriaceous except area between polished antennal sockets (Figs 2, 3); ocellar-ocular length $(\mathrm{OOL}) /$ postero-ocellar length $(\mathrm{POL})=1.05$ (Fig. 2). Frons not concave above each antennal socket; frons with small and distinct tubercle between antennal sockets; antennal sockets large and protruding anteriorly in dorsal view; face 1.2 times as wide as high; inner margins of compound eyes parallel; clypeus strongly convex and transverse, 1.7 times as wide as high, with straight apical margin; anterior tentorial pits large; labrum very wide, 0.8 times as wide as clypeus, with straight apical margin, protruding from under clypeus (Fig. 3). Mandible slender, 3.6 times as long as wide at base, gradually narrowed from base to apex, with lower tooth 0.3 times as long as upper tooth. Malar space 2.2 times as wide as base of mandible. Occipital carina complete and separated from hypostomal carina above base of mandible by 1.4 times width of mandibular base; dorso-median part of occipital carina evenly arched. Maxillary palpus extremely long, reaching epicnemial carina; fifth segment 4.0 times as long as mandibular base (Fig. 1). Flagellum bristle-shaped, very long and slender; apical flagellomere conical; first flagellomere 8.5 times as long as apical width and 1.7 times as long as second one (Fig. 4).

Mesosoma. Collar of pronotum long. Pronotum strigose on coriaceous surface. Mesonotum strongly convex, with notaulus developed to middle of mesonotum; surface of mesonotum granulate with scattered punctures except densely punctate postero-median portion (Fig. 5). Epicnemial carina complete; subalar prominence not sharp; impression below speculum not strong; sternaulus distinct, sharp, almost reaching base of middle coxa; postpectal carina absent; surface of mesopleuron obliquely strigose, except speculum slightly polished (Fig. 6). Scutellum highly elevated above postscutellum, with lateral carina reaching apex and dorsal surface almost flat; hind margin of metanotum with a triangular projection on each side of postscutellum (Figs 5, 7). Propodeum in profile with area basalis flat and evenly slanted from base of area superomedia; regular carinae 


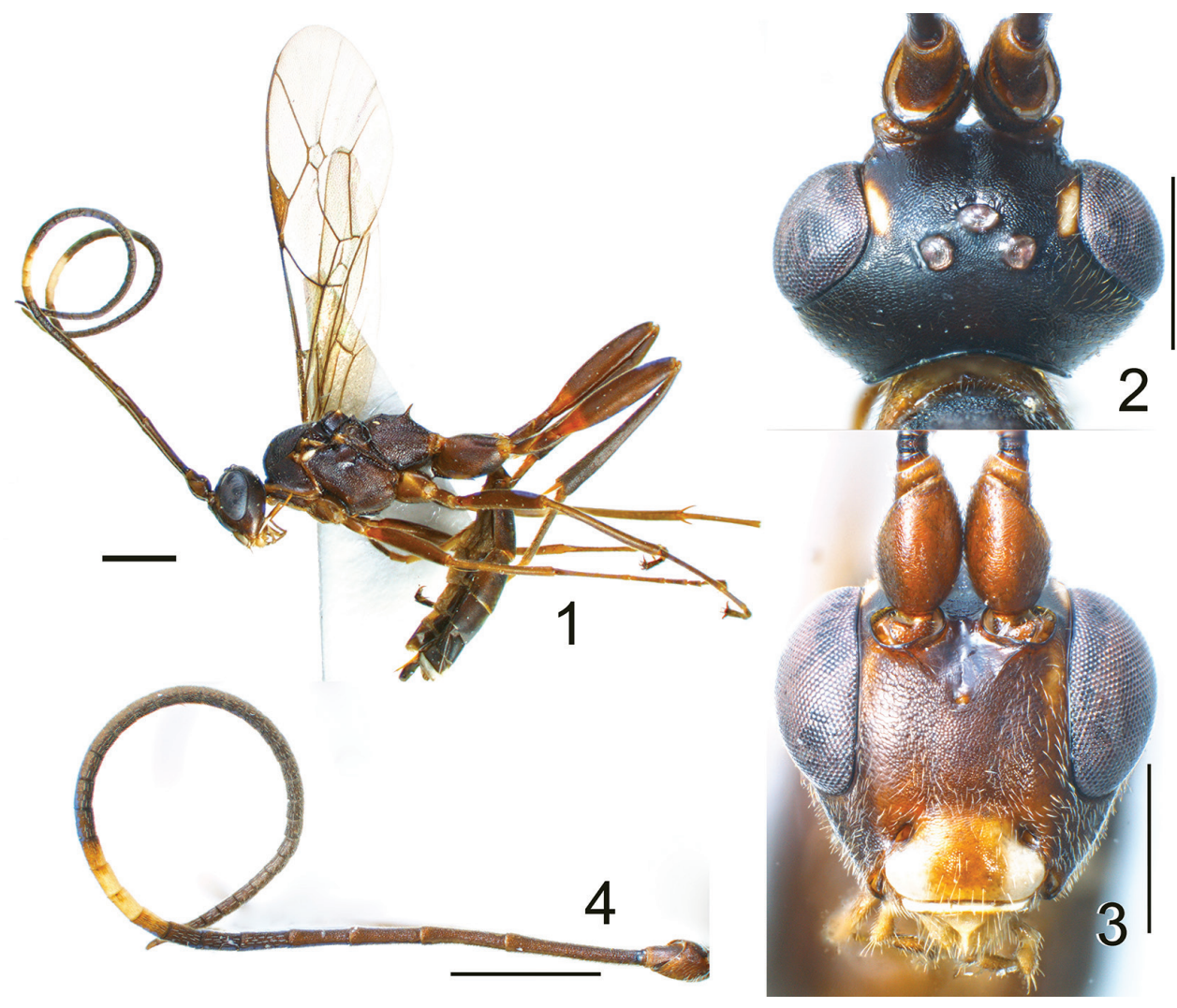

Figures I-4. Heinrichiellus nambui sp. n., Holotype. I habitus $\mathbf{2}$ head in dorsal view $\mathbf{3}$ head in frontal view 4 antenna. Scale bars $=1 \mathrm{~mm}$.

of propodeum complete; basal one-third of juxtacoxal carina distinct; area superomedia pentagonal, 1.1 times as long as wide; apex of area dentiparae with very strongly developed and sharp apophysis, almost perpendicular to surface of propodeum, and the apophysis slightly curved downward or almost straight; surface of propodeum rugose; area metapleuralis strigose (Figs 8, 9). Propodeal spiracle 2.5 times as long as wide.

Legs. Legs very slender and long; all legs longer than fore wing. Hind tibia 9.0 times as long as apical width; ratio of length of tibiae fore:mid:hind $=1.0: 1.3: 1.8$. Tarsal claws not pectinate.

Wings (Fig. 10). Fore wing $5.9 \mathrm{~mm}$ long; areolet 1.8 times as long as $3 r s-m, 0.7$ times as high as $2 m-c u$, pentagonal and almost symmetrical; $1 m-c u, 2 m-c u$, and $3 r s-m$ each with single bulla; $C u-a$ opposite $R s$ \& $M$; ramulus absent. Hind wing with $c u-a$ one-fourth as long as first abscissa of $C u 1$.

Metasoma. Metasoma coriaceous (Figs 11, 12). First tergite in profile almost straight, slightly bent downward at base of postpetiole; in dorsal view 4.6 times as long as wide at base; petiole very long, rounded in cross-section, not flattened, of approximately equal width and height; in dorsal view petiole slightly broadened posteriorly; 

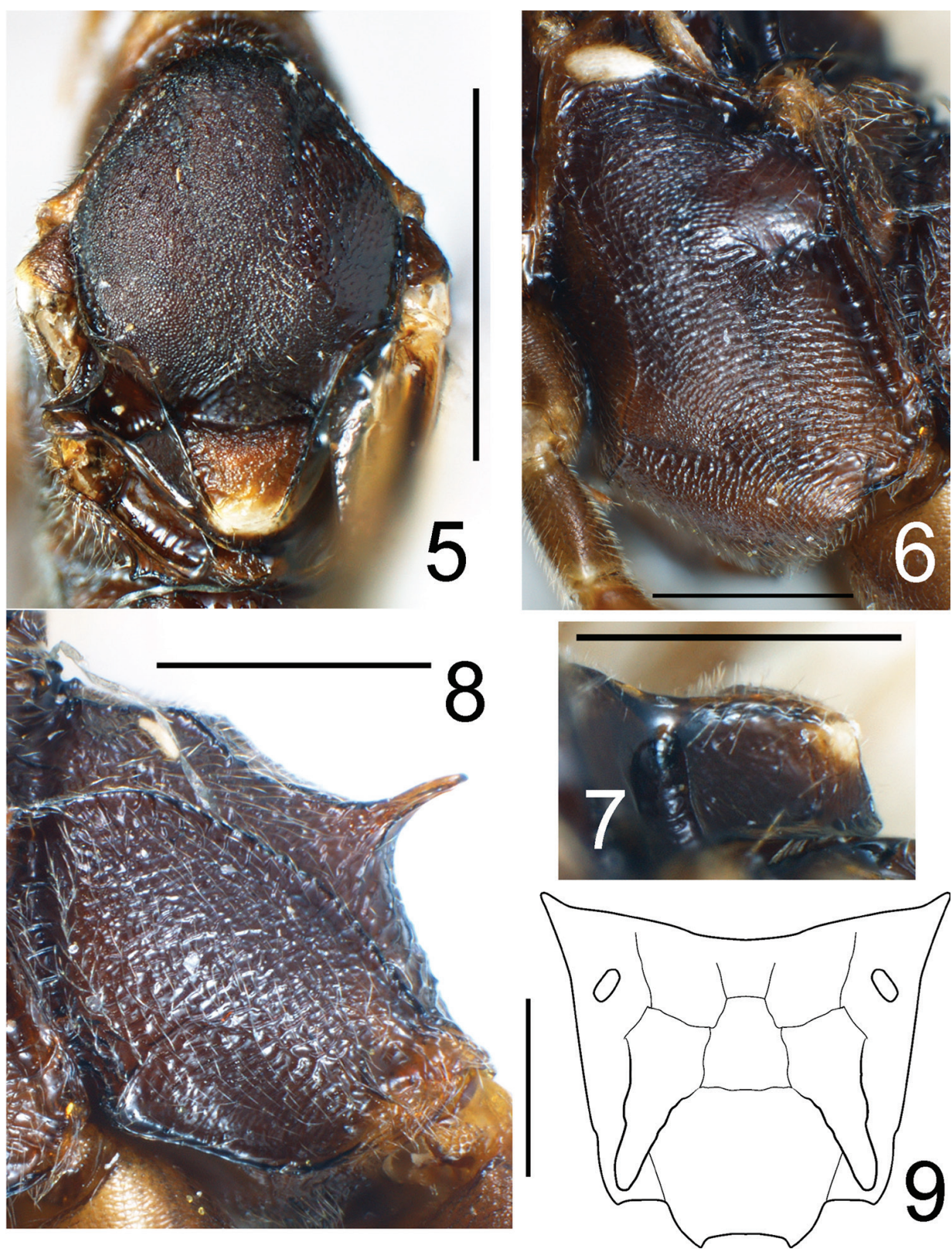

Figures 5-9. Heinrichiellus nambui sp. n., Holotype. $\mathbf{5}$ mesonotum to postscutellum in dorsal view $\mathbf{6}$ mesopleuron $\mathbf{7}$ scutellum in lateral view $\mathbf{8}$ propodeum in lateral view $\mathbf{9}$ carinae of propodeum. Scale bars $=1 \mathrm{~mm}$.

dorso-median carina present only on apical portion of postpetiole (Fig. 11). Second tergite in dorsal view 2.8 times as long as wide at base. Gastrocoelus slightly impressed, in form of longitudinal groove. Thyridium oval, distant from base of second tergite 


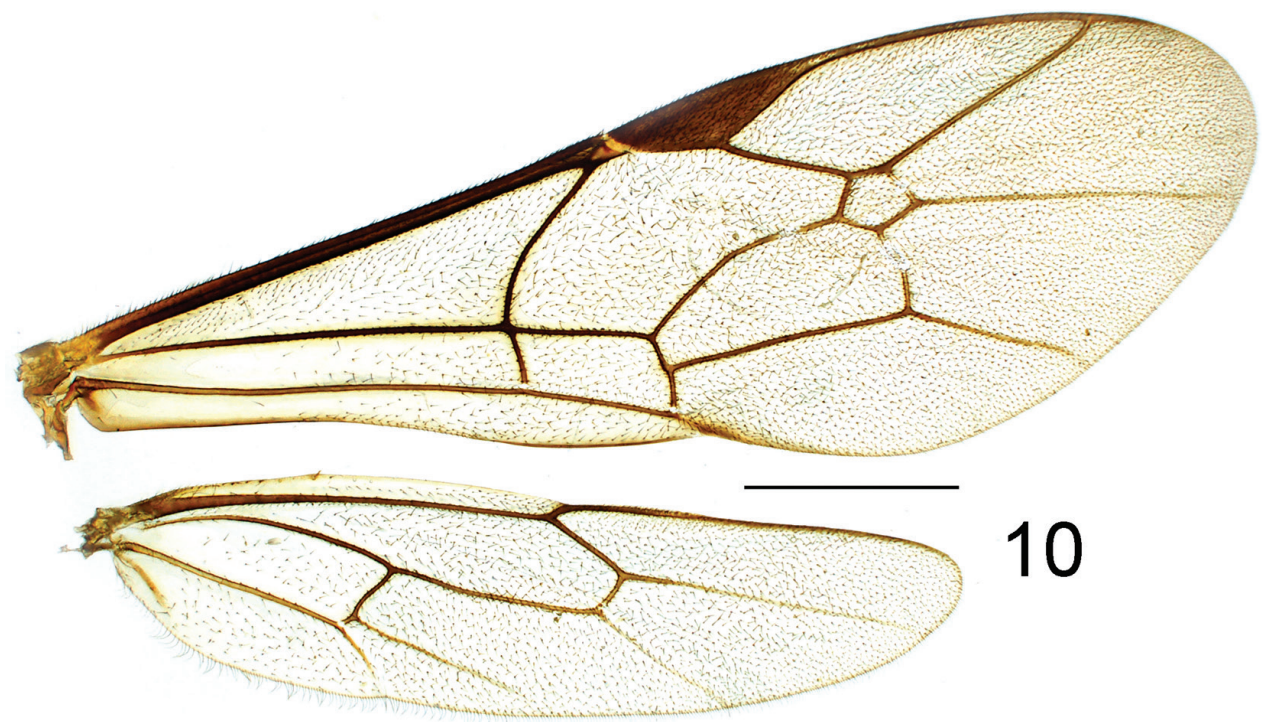

Figure 10. Heinrichiellus nambui sp. n., Holotype, wings. Scale bar $=1 \mathrm{~mm}$.

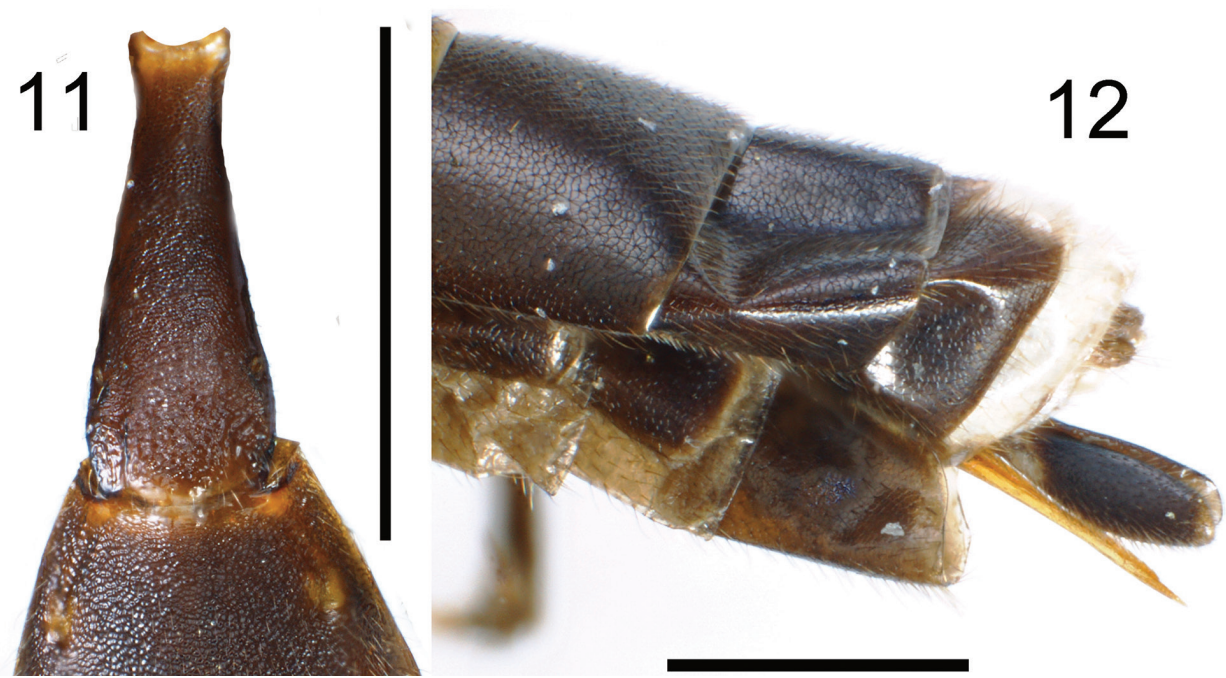

Figures I I-I 2. Heinrichiellus nambui sp. n., Holotype. I I tergite 1 in dorsal view $\mathbf{I} 2$ apex of abdomen in lateral view. Scale bars $=1 \mathrm{~mm}$.

by 0.7 times its length. Tergites 3-6 with laterotergites separated by distinct crease. Sternites 2-5 laterally sclerotized and middle part not sclerotized. Hypopygium with apical margin rounded and longitudinally folded in middle. Ovipositor sheath with apex truncate, protruding beyond apex of metasoma (Fig. 12).

Coloration. Body ground color reddish to blackish brown (Fig. 1). Vertex with a pair of white spots along eye margins (Fig. 2); clypeus whitish brown medially and 


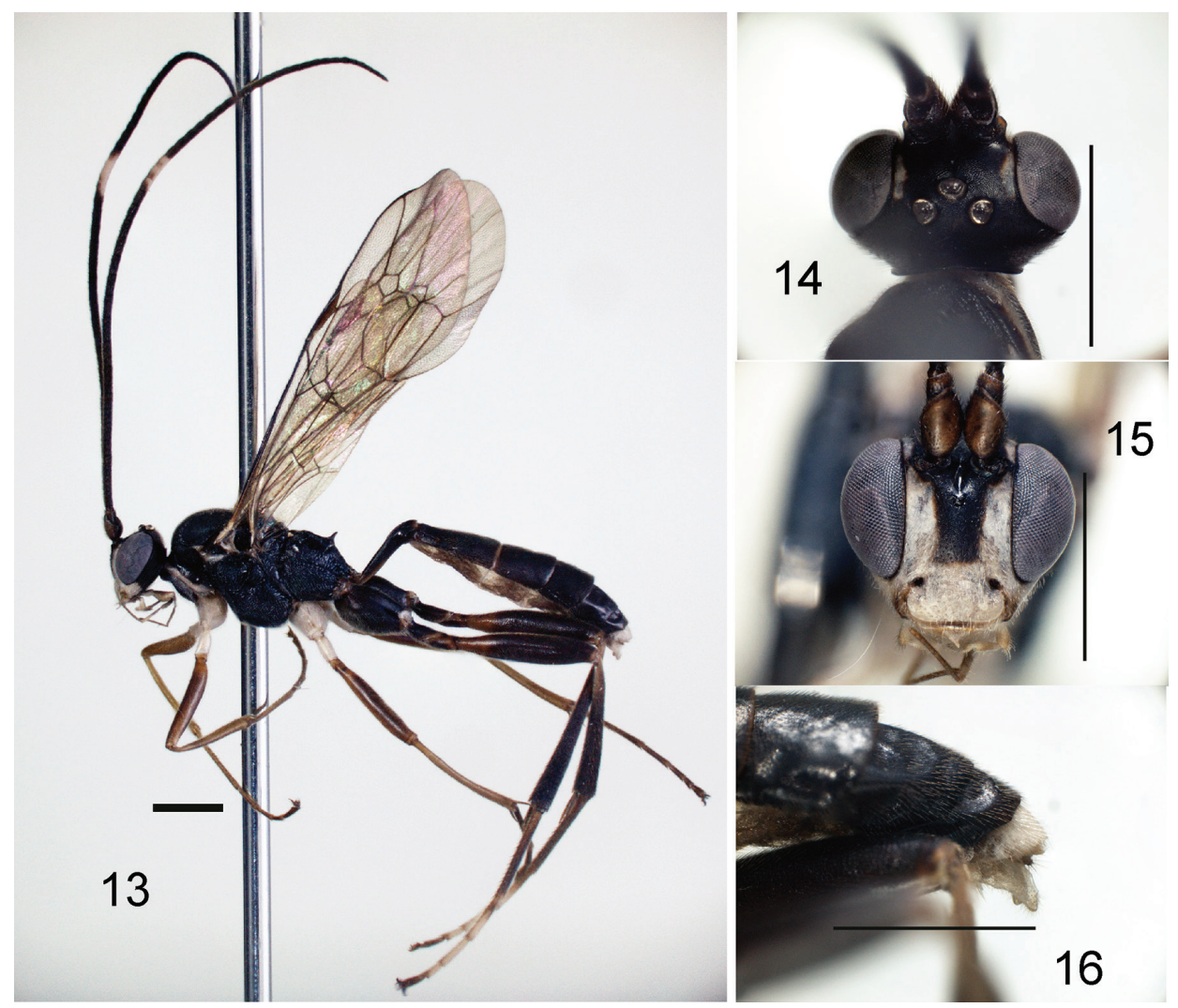

Figures I 3-I 6. Heinrichiellus nambui sp. n., Paratype (male). I $\mathbf{3}$ habitus I $\mathbf{4}$ head in dorsal view I $\mathbf{5}$ head in frontal view; 16, apex of abdomen in lateral view. Scale bars $=1 \mathrm{~mm}$.

white on lateral quarter; maxillary and labial palpi whitish brown; labrum and flagellar annulus (eighth-eleventh flagellomeres) white. Subalar prominence white; scutellum whitish brown on anterior two-third and white on posterior one-third. Metasoma with seventh tergite white. Ovipositor sheath black; basal quarter and apical portion white.

Description of male (Figs 13-17). As in female except for the following characters. Head. $\mathrm{OOL} / \mathrm{POL}=1.33$ (Fig. 14); face 1.5 times as wide as high; clypeus 2.0 times as wide as high (Fig. 15). First flagellomere 7.1 times as long as apical width and 1.5 times as long as the second one.

Mesosoma. Apophysis of propodeum shorter than that in female, almost straight; area superomedia 1.2 times as wide as long.

Metasoma. Genitalia as in Figures 16-17; apex of gonosquama rather narrow and curved downwards. Basal apodeme of aedeagus broadened and curved downwards.

Coloration. Body ground color black to dark brown (Fig. 13). Vertex with a pair of white spots along eye margins (Fig. 14); clypeus and lateral parts of face white; malar space white (Fig. 15); maxillary and labial palpi whitish brown; labrum and flagellar annulus $\left(14^{\text {th }}-17^{\text {th }}\right.$ flagellomeres) white. Collar of pronotum, subalar prominence and 


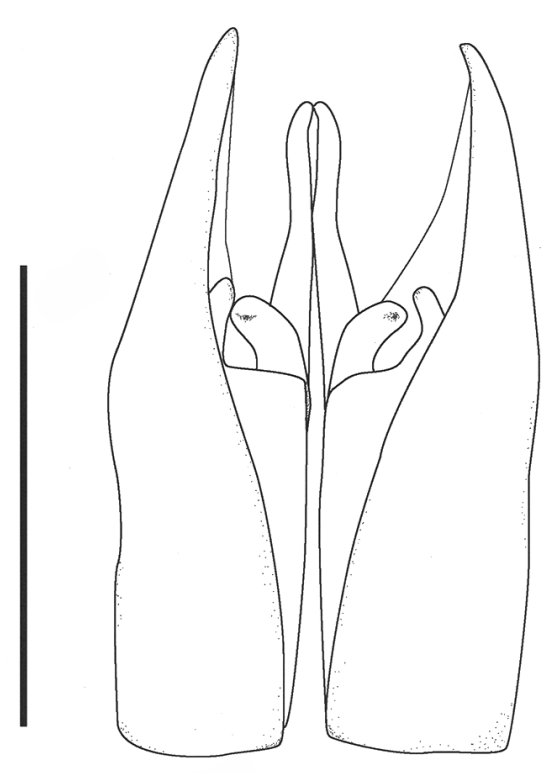

A

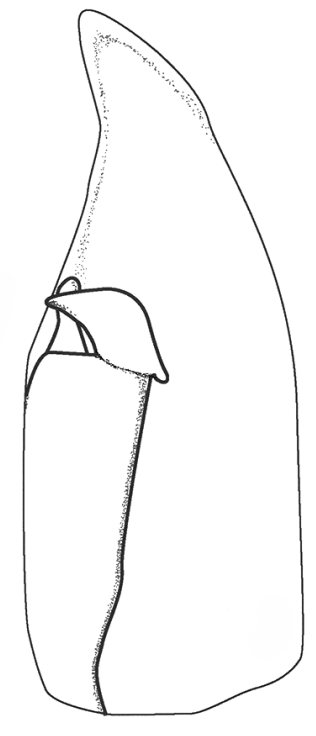

B
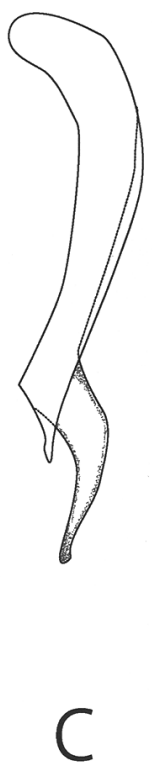

Figure 17. Heinrichiellus nambui sp. n., Paratype (male) genitalia (A ventral view B gonoforceps in mesal view $\mathbf{C}$ aedeagus in lateral view). Scale bar $=0.5 \mathrm{~mm}$.

posterior one-third of scutellum white. Fore- and mid-coxae and trochanters white; fore- and mid-femora and tibiae reddish brown; second-fourth hind tarsomeres whitish brown. Metasoma with seventh tergite and genital capsule white (Fig. 17).

Distribution. Japan (Hokkaido, Honshû).

Etymology. This species is named after Mr. Toshiaki Nambu who collected the holotype.

Remarks. When this new species is compared with the descriptions of another congener, H. hildegardae, by Tereshkin $(1996,2009)$, they can be distinguished on the basis of the following key.

\section{Key to species of the genus Heinrichiellus}

1 Body punctate; mesopleura microsculptured; area superomedia of propodeum long and hexagonal in female, almost square in male; spiracles of propodeum 3 times as long as wide; areolet of fore wing asymmetrical

H. hildegardae Tereshkin

- $\quad$ Body coriaceous with rugosity; mesopleura obliquely strigose; area superomedia of propodeum pentagonal in both sex; spiracles of propodeum 2.5 times as long as wide; areolet of fore wing almost symmetrical ... H. nambui sp. $\mathbf{n}$. 


\section{Discussion}

Heinrichiellus nambui sp. $\mathrm{n}$. is the second species of the genus Heinrichiellus. While the type species of the genus, $H$. hildegardae, was reported from Primorski Krai of Russia, H. nambui was found in Hokkaido and Honshu, Japan. Vegetation of the type locality (Chichibu, Saitama Prefecture) and the locality of the paratypes comprises deciduous broad-leaved forests in the mainland of Japan. Heinrichiellus hildegardae was described based on the characteristics of one female and two males. Similarly, only two females and one male of $H$. nambui could be found; nevertheless, we examined the principal collections of Ichneumoninae in Japan, and these collections included many specimens collected from similar environments as the type locality. The following possibilities might explain the rarity of this genus in collections.

Specimens of Heinrichiellus might often be overlooked as belonging to Cryptinae. Because this genus has a distinct sternaulus similar to that in Cryptinae, this character leads to misidentification. In fact, the paratypes were found in a box of Cryptinae in EUMJ. A well-developed sternaulus is a characteristic of Cryptinae and unusual in Ichneumoninae. Other characteristics such as the form of the clypeus and wing venation can be used for correct identification.

The habitat of Heinrichiellus is not suitable for using the usual methods of collecting wasps, such as sweeping and placement of ground Malaise traps. Recorded hosts of Platylabini mainly belong to Geometridae (Yu et al. 2012) and members of the tribe are known as larval-pupal parasitoids (van Veen 1981, Tereshkin 2009). The metasoma morphology is either amblypygous, which is adapted for attacking larvae, or oxypygous, which is adapted for attacking pupae (Heinrich 1960, Hinz 1983, Sime and Wahl 2002). Although Sime and Wahl (2002) suggested that oxypygous species do not strictly attack pupae, none of the species with an amblypygous metasoma were recorded as pupal parasitoids; this indicates that Heinrichiellus is also a larvalpupal parasitoid. A study on Ichneumon suggested that species with a slender body and long antenna tend to attack hosts pupating above the ground (Tschopp et al. 2013); Heinrichiellus also probably attacks hosts pupating above the ground. Further, many Geometridae species use arboreous plants; to attack the larvae, the habitat of Heinrichiellus might be forest canopy. Thus, canopy Malaise traps might need to be used for collecting such parasitoid wasps.

These findings suggest that Heinrichiellus are more likely to be distributed in a wider area, including other Islands of Japan as well as other Asian countries. Additional studies are warranted to elucidate the distribution pattern of species belonging to this genus.

\section{Acknowledgments}

The first author would like to express his sincere thanks to M. Ôhara (Systematic Entomology, Hokkaido University) and K. Watanabe (Kanagawa Prefectural Museum of Natural History) for their guidance. We thank the following people for allowing us 
to examine the specimens: S. Yoshimatsu (National Institute for Agro-Environmental Sciences), R. Matsumoto (Osaka Museum of Natural History), and A. Shimizu (Tokyo Metropolitan University).

We also thanks to Gavin Broad (the Natural History Museum, London) for making linguistic corrections to this manuscript.

\section{References}

Eady RD (1968) Some illustrations of microsculpture in the Hymenoptera. Proceedings of the Royal Entomological Society of London 43: 66-72.

Gauld ID (1991) The Ichneumonidae of Costa Rica, 1. Memoirs of the American Entomological Institute 47: 1-589.

Hinz R (1983) The biology of the European species of the genus Ichneumon and related species (Hymenoptera: Ichneumonidae). Contributions of the American Entomological Institute 20: $151-152$.

Koçak AÖ, Kemal M (2008) On the nomenclature of a pre-occupied generic name in the family Ichneumonidae (Hymenoptera). Centre for Entomological Studies Ankara. Miscellaneous Papers 150: 1.

Sime KR, Wahl DB (2002) The cladistics and biology of the Callajoppa genus-group (Hymenoptera: Ichneumonidae, Ichneumoninae). Zoological Journal of the Linnean Society 134: 1-56. doi: 10.1046/j.1096-3642.2002.00006.x

Tereshkin A (1996) A new Ichneumoninae Stenopneusticae genus, Heinrichia, from the Far East(Hymenoptera, Ichneumonidae). Entomofauna 17: 89-96.

Tereshkin A (2000) Description of the males of Ulesta nigroscutellata Tereshkin, 1993 and Rhadinodonta rufidens(Wesmael, 1844) and a new name for the genus Heinrichia Tereshkin, 1996 (Hymenoptera, Ichneumonidae, Ichneumoninae Stenopneusticae). Entomofauna 21: 229-234.

Tereshkin AM (2009) Illustrated key to the tribes of subfamilia Ichneumoninae and genera of the tribe Platylabini of World fauna (Hymenoptera, Ichneumonidae). Linzer biologische Beiträge 41(2): 1317-1608.

Tschopp A, Riedel M, Kropf C, Nentwig W, Klopfstein S (2013) The evolution of host associations in the parasitic wasp genus Ichneumon (Hymenoptera: Ichneumonidae): convergent adaptations to host pupation sites. BMC Evolutionary Biology 13: 74. doi: 10.1186/14712148-13-74

van Veen JC (1981) The biology of Poecilostictus cothurnatus (Hymenoptera: Ichneumonidae) an endoparasite of Bupalus piniarius (Lepidoptera: Geometridae). Annales Entomologici Fennici 47: 77-93.

Yu DSK, van Achterberg C, Horstmann K (2012) Taxapad 2012, Ichneumonoidea 2011. Ottawa, Ontario. http://www.taxapad.com [database on flash-drive] 